\title{
Tobacco control and nicotine addiction in Canada: Current trends, management and challenges
}

\author{
Andrew Mclvor MD MSc FRCP
}

\begin{abstract}
A McIvor. Tobacco control and nicotine addiction in Canada: Current trends, management and challenges. Can Respir J 2009;16(1):21-26.
\end{abstract}

Despite a significant decrease in tobacco use over the past four decades, cigarette smoking remains the leading preventable cause of death and disease in Canada. Nicotine addiction, unequal access to available support programs and gaps in continuity of health care are recognized as the main barriers to smoking cessation. To overcome these obstacles and to reach the Federal Tobacco Control Strategy goal of reducing smoking prevalence in Canada from $19 \%$ to $12 \%$ by 2011 , several Canadian health care organizations developed extensive sets of recommendations. Improved access to affordable pharmacotherapies and behavioural counselling, better training of health care professionals and the addition of systemic cessation measures appear to be the key components in all of the proposed recommendations.

The present article provides an overview of the current approaches to smoking cessation in Canada, describes the remaining challenges, and outlines recent recommendations that are geared toward not only tobacco control but also overall improvement in long-term health outcomes.

\section{Lutte antitabac et dépendance à la nicotine au Canada : Tendances, gestion et défis actuels}

Malgré une baisse significative de la consommation de tabac depuis quatre décennies, la cigarette demeure la principale cause modifiable de mortalité et de maladie au Canada. La dépendance à la nicotine, l'accès inégal aux programmes antitabagiques offerts et un suivi médical insuffisant constitueraient les principaux obstacles à l'abandon du tabac. Pour surmonter ces obstacles et pour atteindre l'objectif de la Stratégie fédérale de lutte contre le tabagisme, soit ramener le taux de tabagisme au Canada de $19 \%$ à $12 \%$ d'ici 2011, plusieurs organismes de soins de santé canadiens ont élaboré des séries complètes des recommandations à cet effet. Un accès plus facile à des thérapies pharmacologiques et comportementales abordables, la formation ciblée des professionnels de la santé et l'application systématique de mesures antitabagiques sont au cœur de toutes les directives proposées.

Le présent article fait le point sur les approches antitabagiques actuelles au Canada, explique les défis qu'il reste à relever et résume les récentes recommandations axées, non seulement sur la lutte antitabac, mais également sur l'amélioration globale de la santé des individus à long terme.

Key Words: Nicotine addiction; Respiratory health; Smoking cessation

$\mathrm{O}$ ver the past four decades, cigarette smoking has decreased considerably in Canada, from an estimated 50\% in 1965 to a current rate of $19 \%$ (1). Moreover, smoking rates have dropped in the critical 15 to 19 year age group from over $40 \%$ in the early 1980 s, to $28 \%$ in 1999 , and to $15 \%$ in 2006 (1). A variety of successfully implemented control measures including taxation, consumer regulation and limitation of advertising contributed to these encouraging results. In fact, Canada is recognized as a world leader in the adoption of populationbased smoking cessation approaches, such as warning labels on cigarette packages, public information and the introduction of smoke-free legislation. In March 2004, Ireland became the first country in the world to create smoke-free indoor workplaces and public places, including restaurants, bars and pubs (2). Within three months, Norway's smoke-free legislation entered into force. Since then, these examples have been followed by many countries including Canada. Currently, approximately $90 \%$ of Canadians live in areas where public spaces and workplaces are smoke-free, compared with $50 \%$ of Americans (3). While most developed countries are adopting population-based smoking cessation approaches, it is also important to note that cessation therapies are not available in all parts of the world. In fact, services to treat tobacco dependence are fully available in only nine countries, $5 \%$ of the world's population (2).

Nevertheless, there are still approximately 4.5 million smokers in this country, and an estimated 37,000 Canadians will die in 2008 from smoking-related diseases, including 1000 from second-hand smoke (4). It is also alarming that the current smoking rate for First Nations adults on reserves is approximately triple the rate for Canadians in general (58.8\%) (5). For nonreserve Aboriginal peoples, the rate is more than double the general population (5). Tobacco use among young adults also remains a difficult challenge. Among 20- to 24-yearolds, the rate of smoking actually increased between 2005 and 2006 (6). Thus, a significant amount of work is still ahead of us. After all, tobacco is the only legal drug for which the government's declared objective is to entirely stop its use rather than promote safe or responsible consumption, as it does with alcohol. In August 2007, the Federal Tobacco Control Strategy set a goal to further reduce smoking prevalence in Canada from $19 \%$ to $12 \%$ by 2011 (7). Additionally, the aim is to reduce the prevalence of smoking among 15 - to 17 -year-olds from $15 \%$ to 
TABLE 1

Percentages of survey participants who agreed that "Nicotine addiction is why so many people keep smoking even when they want to quit"

\begin{tabular}{|c|c|c|c|c|}
\hline \multirow[b]{2}{*}{$\begin{array}{l}\text { Smokers, } \\
\mathrm{n}=2002\end{array}$} & \multicolumn{3}{|c|}{ Nonsmokers } & \multirow[b]{2}{*}{$\begin{array}{c}\text { Other health care } \\
\text { n=39 }\end{array}$} \\
\hline & $\begin{array}{c}\text { Ex-smokers, } \\
n=1296\end{array}$ & $\begin{array}{l}\text { living with } \\
\text { smokers, } \\
\text { n=898 }\end{array}$ & $\begin{array}{c}\text { Family } \\
\text { physicians, } \\
n=200\end{array}$ & \\
\hline $87 \%$ & $86 \%$ & $85 \%$ & $93 \%$ & $88 \%$ \\
\hline
\end{tabular}

Data adapted from reference 6

9\% and to reduce the prevalence of Canadians exposed to second-hand smoke from $28 \%$ to $20 \%$ (7).

The present article provides an overview of the fundamental approaches to tobacco control in Canada, identifies remaining challenges, and outlines recently described quality improvements that should be considered as integral components of a comprehensive nationwide smoking cessation strategy.

\section{BARRIERS TO SMOKING CESSATION}

Addictive nature of smoking

The Canadian Lung Association recently published a report entitled "Making Quit Happen - Canada's Challenges to Smoking Cessation" (6). According to this report, the vast majority of smokers (over 90\%) expressed at least some desire to quit smoking. However, there are numerous barriers to their success, primarily habit and addiction (Table 1) (6). This is not surprising, because nicotine is one of the most addictive substances used by humans. Its addictive power poses significant challenges to smoking cessation efforts at both the individual and the population levels (7). Thus, tobacco dependence should be considered a chronic disease that often requires repeated intervention and multiple attempts to quit.

\section{Unequal access to cessation programs}

There are many types of smoking cessation programs available to Canadians (see Appendix). Almost all of them aim to provide smokers with an incentive to quit, information to guide them through the process, and tools and strategies to help them along the way. Although most of these programs are provided free of charge, access to smoking cessation programs, medications and support is not universal for all people living in Canada. People living in remote and rural areas, for example, may not have full access to online support, help lines or counselling (6).

Nonpharmacological cessation strategies include brief interventions, such as patient education and advice, behavioural therapy, self-help materials and telephone counselling. However, it is important to keep in mind that not all counselling resources and programs are equally effective (8). For example, standard self-help materials may increase quit rates compared with no intervention, but the effect is likely to be minimal (9). Group therapy, on the other hand, has proven to be better in helping people stop smoking than self-help and other less intensive interventions (10). There is also evidence that materials that are tailored for individual smokers are more effective than untailored materials. However, the absolute size of the effect is small (9). Proactive support lines may also help smokers interested in quitting, and call-back counselling

\section{TABLE 2}

The effect of physician advice on cessation

\begin{tabular}{ll}
\hline Intervention & OR \\
\hline No advice to quit & 1.0 \\
Minimal physician advice to quit & 1.3 \\
Low-intensity counselling (3-10 min) & 1.6 \\
High-intensity counselling (>10 min) & 2.3 \\
\hline
\end{tabular}

Data adapted from reference 16

enhances their usefulness. However, while one or two brief calls are less likely to provide a measurable benefit, three or more calls increase the odds of quitting compared with a minimal intervention such as providing standard self-help materials, brief advice or pharmacotherapy alone (11).

\section{Demographic and socioeconomic factors}

The effect of various demographic and socioeconomic factors on the use of smoking cessation therapies and smoking cessation rates varies in the literature. Several studies have found age, sex and race to be predictive of successful smoking cessation $(12,13)$.

Higher income, education level and social status have also been linked to the use of smoking cessation medications and of quitting. According to a study conducted by Whalen et al (14), smokers with higher education levels and those with private drug insurance coverage were more likely to use smoking cessation agents. Although employment and income were not related to the use of these agents, the authors speculated that the impact of income and education on smoking cessation medication use may be related to having private drug insurance plan coverage.

Gaps in continuity of health care

Gaps in continuity of health care present another challenge. While available data indicate that physician advice plays a powerful role in enhancing spontaneous smoking cessation rates (Table 2) (15), the survey conducted by the Canadian Lung Association indicates that in Canada only a few health care professionals ( $18 \%$ of family physicians and $16 \%$ of others) have had any formal training in smoking cessation counselling (6). However, family physicians consider themselves to be very involved with their patients' smoking cessation. The great majority (92\%) indicated that they discuss smoking with their patients on a regular basis (Figure 1A), compared with only approximately one-half ( $54 \%$ ) of other health care professionals (Figure 1B) (6). Most physicians are also aware of the ' $5 \mathrm{As}$ ' (Ask, Advise, Assess, Assist, Arrange) protocol that was developed to provide a plan for maximizing the likelihood of a successful quit attempt for patients. However, according to recent studies, while approximately $40 \%$ to $50 \%$ of physicians ask their patients about their smoking status and advise them to quit, the rates of assistance with the development of a plan, as well as with follow-up or referrals, are much lower at $1 \%$ to $20 \%(16)$.

In addition, a physician's own smoking status appears to be a critically important determinant of how their patient's tobacco use is addressed. According to a recently published article by Pipe et al (17), physician smokers are less willing to inquire about tobacco use, to advise cessation and to provide 
evidence-based assistance than their nonsmoking counterparts. They are also less likely to believe that smoking posed a significant threat to patient health and less likely to identify smoking cessation as a high priority for intervention. Among the 128 Canadian physicians that participated in this multinational study, 28 (22\%) indicated that they were smokers themselves. The findings of the study suggest that specific programs and strategies should be developed to assist clinicians who smoke with cessation support, because their own smoking behaviour may hinder their clinical efforts and interventions to assist smokers to quit.

In summary, it is evident that the delivery of evidence-based counselling and follow-up, in the primary care setting, requires further assistance. Additionally, many physicians believe that they are unable to help smokers because of the difficulties in promoting change in people who are unwilling, resistant or unmotivated. To that end, recent evidence in support of the concept of motivational interviewing, as an aid in smoking cessation, should be considered (18-20). This patient-centred style of counselling provides a useful vehicle for building rapport and helping patients overcome their resistance to changing their smoking habits.

\section{PHARMACOTHERAPY FOR SMOKING CESSATION}

Over the past 20 years, the ability to effectively help smokers has significantly improved. This improvement is mainly due to the complementary use of smoking cessation pharmacotherapy with brief counselling or behavioural therapy.

In general, smoking cessation medications in Canada fall under two main categories: nicotine replacement therapy (NRT) that can be purchased over the counter, and medications that are available only by prescription (bupropion [Zyban, Biovail Pharmaceuticals, Canada] and varenicline [Champix, Pfizer, Canada]).

\section{NRT}

NRTs available in Canada include nicotine gum, patches and inhalers. This well-established treatment can double the likelihood of smoking cessation (OR 1.77, 95\% CI 1.66 to 1.88) (21). It is formulated to provide nicotine to the body in controlled doses, replacing the nicotine the body is no longer receiving from tobacco. With NRT, nicotine plasma levels remain relatively constant, preventing a fall below the threshold that causes the urge to smoke and the emergence of withdrawal symptoms. The approximate cost of these therapies in Canada varies from $\$ 2.50$ per day for Nicorette gum (Johnson $\&$ Johnson, Canada) to $\$ 4.50$ per day for Nicorette inhaler (Johnson \& Johnson, Canada).

\section{Bupropion (Zyban)}

Bupropion hydrochloride comes in a pill format and was originally developed as an antidepressant (Wellbutrin, Biovail Pharmaceuticals, Canada). While still available for that purpose, it was approved by Health Canada nine years previously for use as a smoking cessation aid (the approximate cost is $\$ 1.60$ per day or $\$ 134.40$ for the 12 -week therapy). It is believed that bupropion possesses noradrenergic and dopaminergic properties, reducing cravings and other withdrawal symptoms. Bupropion doubles the effectiveness of any quit attempt (22) and, until recently, was considered the most effective of

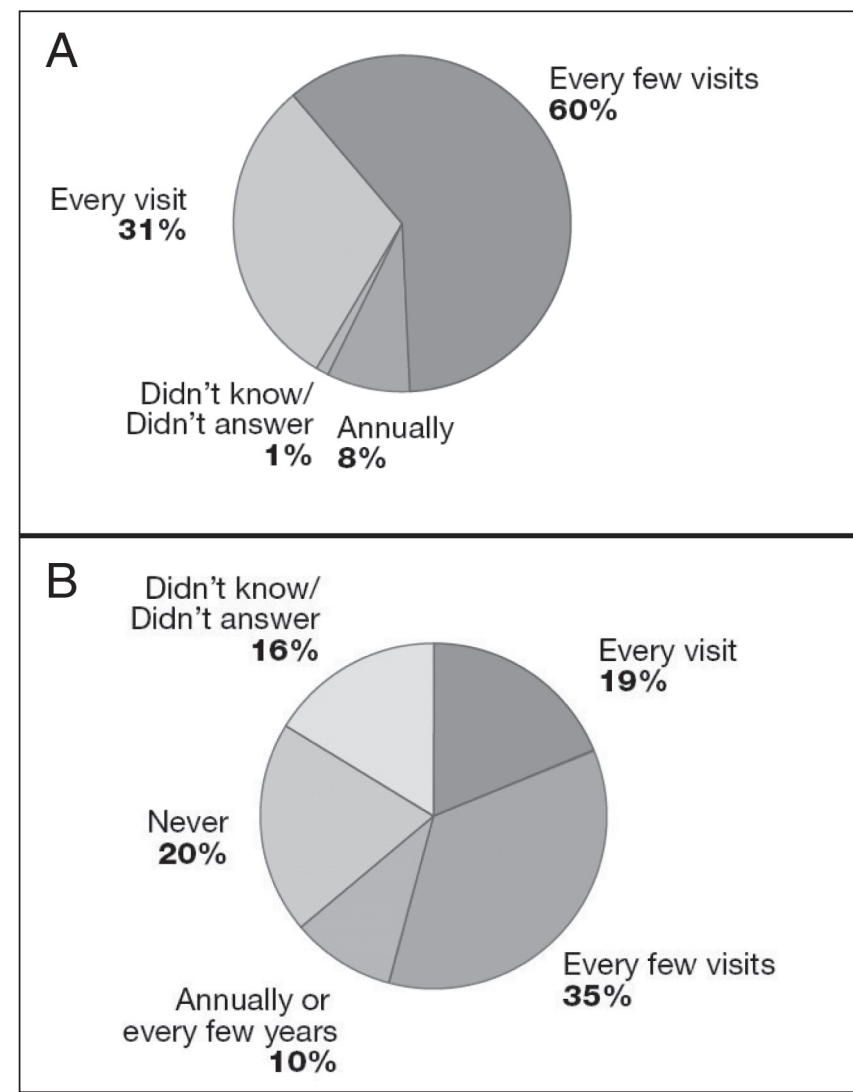

Figure 1) Initiation of smoking cessation-related discussion by health care professionals. A Family physicians discuss quitting with patients. B Other health care professionals discuss quitting with patients. Reproduced with permission from reference 6

all treatment options. It is also important to note that bupropion can be combined with NRT.

\section{Varenicline (Champix)}

A new agent, varenicline, was introduced in Canada in April 2007. Varenicline is the first partial agonist of the $\alpha 4 \beta 2$ nicotinic acetylcholine receptor. It works by stimulating dopamine, which results in reduced cravings and withdrawal symptoms (23). The drug also blocks nicotine receptors, which prevents the dopamine release associated with nicotine consumption. Varenicline is not a nicotine product, and cannot be used in combination with NRT. The drug is known to be substantially excreted by the kidney, and does not appear to interact with any commonly prescribed medications (23).

In direct comparisons, varenicline was found to be approximately four times more effective than placebo (OR 3.85, 95\% CI 2.69 to 5.50) (24), and approximately twice as effective as bupropion (OR 1.90, 95\% CI 1.38 to 2.62) (24). In these comparisons bupropion was not used in combination with NRT.

According to a recent meta-analysis, varenicline, bupropion and the five NRTs studied (gum, inhaler, nasal spray, tablet and patch) were more efficacious than placebo at promoting smoking cessation, with ORs of approximately 2 (Figure 2) (25). Furthermore, in the single hierarchical meta-analysis of all of the trials, it was found that point estimates favoured varenicline over the other pharmacotherapies (25). In addition, 


\begin{tabular}{|c|c|c|c|}
\hline Pharmacotherapy & Odds ratio $(95 \% \mathrm{Crl})$ & $\longleftarrow_{\text {placebo }}^{\text {Favours }}$ & $\begin{array}{l}\text { Favours } \\
\text { treatment }\end{array}$ \\
\hline Bupropion & $2.12(1.76-2.56)$ & & - \\
\hline Nicotine gum & $1.65(1.37-2.01)$ & & - \\
\hline Nicotine inhaler & $2.18(1.38-3.45)$ & & $\bullet$ \\
\hline Nicotine nasal spray & $2.37(1.57-3.60)$ & & $\bullet-$ \\
\hline Nicotine patch & $1.88(1.60-2.22)$ & & - \\
\hline Nicotine tablet & $2.06(1.47-2.87)$ & & $\bullet-$ \\
\hline \multirow[t]{3}{*}{ Varenicline } & $2.55(1.99-3.24)$ & & $\bullet$ \\
\hline & & 0.2 & 7.0 \\
\hline & & \multicolumn{2}{|c|}{ Odds ratio ( $95 \%$ Crl) } \\
\hline
\end{tabular}

Figure 2) Summary estimates of the effect of pharmacotherapies for smoking cessation on the odds of smoking cessation. Smoking cessation is defined by the most rigorous criterion of abstinence. Data have been adjusted for mean age, sex and mean number of cigarettes per day. CrI Credible interval. Reproduced with permission from reference 25

varenicline therapy may increase the proportion of patients who are abstinent compared with bupropion therapy; however, the credible interval is wide, and these results are not definitive (OR 1.40, 95\% credible interval 0.75 to 2.66) (25). Recently, the United Kingdom National Institute for Health and Clinical Excellence review (26) of varenicline concluded that varenicline was "superior to NRT and bupropion in achieving continuous abstinence" and that its use in smoking cessation was "likely to be a cost-effective use of National Health Service (NHS) resources".

Varenicline is started at a dose of $0.5 \mathrm{mg} /$ day. However, to optimize opportunity for the success of the therapy, patients should be titrated up to the maximum recommended dose of $1 \mathrm{mg}$ twice daily. The approximate cost of varenicline (Champix) in Canada is $\$ 3.37$ per day or $\$ 278.03$ for the 12 -week therapy. A reduction in the dose is recommended only in patients with severe renal disease or for patients who cannot tolerate the adverse effects of varenicline. Nausea is the most common side effect; however, it is seldom severe enough to warrant discontinuation. Approximately 3\% of participants taking varenicline in clinical trials experienced nausea to the extent that it required discontinuation.

Recently, the US Food and Drug Administration issued an alert concerning an increase in serious neuropsychiatric symptoms in patients taking varenicline (27). In Canada, Pfizer, in collaboration with Health Canada, issued a letter notifying health care professionals of postmarketing reports of serious neuropsychiatric adverse events possibly associated with Champix (28). The Canadian product monograph for Champix was revised accordingly (23). However, regardless of the observed increase in neuropsychiatric symptoms, it is known that smoking cessation with or without treatment may be associated with nicotine withdrawal symptoms and the exacerbation of underlying psychiatric illness. Furthermore, it is important to note that postmarketing adverse events are reported voluntarily from a population of uncertain size. Thus, it is not always possible to establish a causal relationship to drug exposure.

Despite the documented efficacy of smoking cessation phamacotherapies, Eisenberg et al (25), via a meta-analysis study of randomized controlled trials, reported the point prevalence of abstinence at 12 months to be well under 30\% among patients in the drug treatment groups. With continuous abstinence as the outcome measure, the rate of abstinence was even lower. Consequently, there is a need to identify optimal cessation strategies, including alternative ways to use existing agents.

\section{WHAT ENCOURAGES SMOKERS TO QUIT?}

The increasing cost of cigarettes, according to a survey conducted by the Canadian Lung Association, was recognized as one of the encouraging factors to quit indicated by both smokers and ex-smokers (6). Ex-smokers also indicated other encouraging factors, such as pressure from family and friends (64\% of responders), and fewer public places allowing smoking (53\% of responders). On the other hand, smokers and nonsmokers living with smokers indicated that the greatest motivation for quitting would come from being diagnosed with a health problem (over $70 \%$ of responders).

\section{HOSPITAL SETTING AND CHRONIC DISEASE MANAGEMENT MODELS}

An admission to hospital provides an opportunity to help people stop smoking. This is a time when perceived vulnerability to dangers from smoking and motivation for quitting may be highest. Individuals may also find it easier to quit in an environment where smoking is restricted or prohibited. Thus, initiating smoking cessation during hospitalization may help more people make and sustain a quit attempt. According to a recent analysis, intensive counselling interventions that began during a hospital stay, and continued with supportive contacts for at least one month after discharge, increased smoking cessation rates after discharge (OR 1.65, 95\% CI 1.44 to $1.90 ; 17$ trials) (29). No statistically significant benefit was found for less intensive counselling interventions. Importantly, the data indicated that the efficacy of the counselling intervention did not vary according to a smoker's admitting diagnosis. This suggests that it is appropriate to offer the intervention to all hospitalized smokers regardless of their admitting diagnosis.

Furthermore, in several randomized trials of hospital patients receiving smoking cessation interventions, brief counselling combined with an NRT has been found to be more effective than counselling alone (30-32). However, a recent study by Lacasse et al (33) demonstrated that a smoking cessation intervention of moderate intensity (education and psychological support, with or without pharmacological therapy, associated with follow-up phone calls) delivered in a tertiary cardiopulmonary centre is not sufficient to increase the smoking cessation rate at one-year follow-up.

The University of Ottawa Heart Institute model is an example of a successfully implemented hospital-based smoking cessation program in Canada (34). The goal of the program is to increase the number of smokers who are abstinent from smoking six months after a coronary artery disease-related hospitalization. The model involves an exceptional combination of personal consultation and intervention, information, follow-up and feedback. Core elements are documentation of smoking status at hospital admission, inclusion of cessation intervention on patient charts, individualized bedside 
counselling, the appropriate and timely use of NRT, automated telephone follow-up after discharge and referral to outpatient cessation resources. According to a recent update by Reid et al (34), 91\% of smokers (identified at admission) received intervention to help them quit smoking. At a sixmonth follow-up, $44 \%$ were smoke-free, which was a $15 \%$ absolute increase over a previous institutional cessation rate. The 'Ottawa model' approach indicates the existence of a high impact opportunity for the delivery of care and smoking cessation counselling that should be initiated in all Canadian hospitals.

\section{TOBACCO CONTROL MEASURES IN CANADA AND THE UNITED STATES: RECENT DEVELOPMENTS AND RECOMMENDATIONS}

A recently published update (35) of the Canadian Thoracic Society recommendations for the management of chronic obstructive pulmonary disease (COPD) calls for a systematic approach with every smoker, and recommends intensive counselling combined with pharmacotherapy whenever possible. Both the Canadian Lung Association and Ontario Lung Association have also recognized the need for a more integrated approach. Thus, both associations are moving away from asthma, or COPD, or nicotine addiction as isolated diseases and encouraging a broader 'lung health management' that will incorporate COPD initiatives with provincial activities related to smoking as well as general prevention of chronic diseases $(36,37)$.

An interesting and somewhat intriguing proposition was recently made by the Institute of Medicine, a prestigious group of health experts in the United States. In a report entitled "Ending the Tobacco Problem: A Blueprint for the Nation", the Institute suggests a shift in focus to tobacco manufacturers and recommends that federal health authorities (ie, the Food and Drug Administration in the United States, and Health Canada) should have the right to regulate tobacco products like other drugs (38). For example, as with other regulated drugs, the amount of the active ingredient (in this case the amount of nicotine in each cigarette) should be fully disclosed on the package. The report also calls for all private and public health plans to cover smoking cessation aids and programs, as well as for dramatic increases in health promotion budgets, suggesting per capita spending of approximately US $\$ 15$ to US $\$ 20$ on tobacco control. Currently, Canada spends approximately $\$ 4$ per capita or $\$ 131$ million a year on antismoking campaigns (6). However, no Canadian benchmarks have been developed to suggest appropriate levels of investment in tobacco control. Such benchmarks could help facilitate the achievement of goals set by both federal and provincial smoking cessation strategies.

In Canada, smoking cessation medications are classified as 'lifestyle' drugs and as such are excluded from most of the country's public health plans. In fact, Quebec is the only province in which smoking cessation medications are listed on provincial formulary. However, a recent study (39) suggests that a substantial population of smokers (58.9\%) would be willing to participate in public health initiatives to reduce the prevalence of smoking through the distribution of free NRT. Of those interested, almost all (93.8\%) indicated that they would use the NRT to help them quit for good.
To that end, it is important to note that one of the key recommendations of the Canadian Lung Association is to improve access to affordable medications for all people living in Canada by including all medications on provincial formularies and drug coverage plans (6). Similarly, the 2008 update of the US Guidelines for Treating Tobacco Use and Dependence urges health systems, insurers and purchasers to assist clinicians in making effective smoking cessation treatments available to their patients (40).

Additional recommendations advocated by the Canadian Lung Association include improved and expanded surveillance, better access to programs and trained counselors, training for family physicians and other health care professionals, and culturally relevant cessation support for Aboriginal peoples (6).

\section{SUMMARY}

Although important advances in reducing tobacco use have been made over the past two decades, further substantial and enduring decline rates cannot be achieved by expecting past successes to continue. Thus, aggressive policy initiatives will be necessary to end the tobacco problem. Improved access to affordable pharmacotherapies and behavioural counselling, better training of health care professionals, and the addition of systemic cessation measures are key recommendations to further reducing smoking rates in Canada. All health care professionals, irrespective of their specialties, need to develop efficient and consistent approaches to identifying and assisting smokers in their attempts to quit. There is substantial room to improve the overall cessation outcome rates through cessation policies that support a comprehensive care management network with aligned financial incentives at both federal and provincial levels.

\section{Smoking cessation resources}

\section{APPENDIX}

Canadian Cancer Society <www.cancer.ca>

Canadian Council for Tobacco Control <www.cctc.ca $>$

Canadian Lung Association <www.lung.ca $>$

Clinical Tobacco Intervention Program <www.omacti.org $>$

Go Smokefree (Health Canada) <www.hc-sc.gc.ca/hl-vs/tobac-tabac/ index_e.html>

Heart \& Stroke Foundation of Canada <http://heartandstroke.com>

On the Road to Quitting. Guide to becoming a non-smoker

$<$ http://www.hc-sc.gc.ca/hl-vs/pubs/tobac-tabac/orq-svr/index-eng.php>

Physicians for a Smoke-Free Canada <www.smoke-free.ca>

Public Health Agency of Canada <www.phac-aspc.gc.ca $>$

Quit4Life (Health Canada) <www.quit4life.com>

Smokers' Helpline (Canadian Cancer Society)

$<$ www.smokershelpline.ca>

Smoking Cessation Guidelines. How to Treat your Patient's Tobacco Addiction < www.smoke-free.ca/pdf_1/smoking_guide_en.pdf>

Stupid.ca <www.stupid.ca>

\section{REFERENCES}

1. Health Canada. The National Strategy: Moving Forward. The 2006 Progress Report on Tobacco Control. <http://www.hc-sc.gc.ca/hl-vs/ alt_formats/hecs-sesc/pdf/pubs/tobac-tabac/prtc-relct-2006/prtcrelct-2006-eng.pdf> (Version current at July 22, 2008).

2. World Health Organization. WHO report on the global tobacco epidemic, 2008 - The MPOWER packgage. < http://www.who.int/ tobacco/mpower/en/index.html $>$ (Version current at October 22, 2008). 
3. Pan American Health Organization. World Health Organization. Smoke-free inside, 2007. < http://www.paho.org/english/ad/sde/ra/ Engbrochure.pdf> (Version current at October 22, 2008).

4. Health Canada. About Tobacco Control. <http://www.hc-sc.gc.ca/ hl-vs/tobac-tabac/about-apropos/index_e.html> (Version current at July 22, 2008).

5. Assembly of First Nations. First Nations Regional Longitudinal Health Survey (RHS) 2002/03. <http://rhs-ers.ca/english/pdf/rhs2002 -03reports/rhs2002-03-technicalreport-afn.pdf $>$ (Version current at July 28, 2008).

6. The Canadian Lung association. Making Quit Happen - Canada's Challenges to Smoking Cessation. <http://www.lung.ca/_resources/ Making_quit_happen_report.pdf $>$ (Version current at July 28, 2008).

7. Health Canada. Healthy Living: Federal Tobacco Control Strategy. $<$ http://www.hc-sc.gc.ca/hl-vs/tobac-tabac/about-apropos/role/ federal/strateg-eng.php> (Version current at July 28, 2008).

8. Cahill K, Moher M, Lancaster T. Workplace interventions for smoking cessation. Cochrane Database Syst Rev 2008:CD003440.

9. Lancaster T, Stead LF. Self-help interventions for smoking cessation. Cochrane Database Syst Rev 2005:CD001118.

10. Stead LF, Lancaster T. Group behaviour therapy programmes for smoking cessation. Cochrane Database Syst Rev 2005:CD001007.

11. Stead LF, Perera R, Lancaster T. Telephone counselling for smoking cessation. Cochrane Database Syst Rev 2006:CD002850.

12. D'Angelo ME, Reid RD, Brown KS, Pipe AL. Gender differences in predictors for long-term smoking cessation following physician advice and nicotine replacement therapy. Can J Public Health. 2001;92:418-22.

13. Coambs RB, Li S, Kozlowski LT. Age interacts with heaviness of smoking in predicting success in cessation of smoking. Am J Epidemiol 1992;135:240-6.

14. Whelan AM, Cooke CA, Sketris IS. The impact of socioeconomic and demographic factors on the utilization of smoking cessation medications in patients hospitalized with cardiovascular disease in Nova Scotia, Canada. J Clin Pharm Ther 2005;30:165-71.

15. Health Canada. Nicotine Addiction. General Overview. $<$ http://www.hc-sc.gc.ca/hl-vs/tobac-tabac/res/news-nouvelles/ nicotine-eng.php> (Version current at July 28, 2008).

16. Fiore MC, Bailey WC, Cohen SJ, et al. Treating Tobacco Use and Dependence. Clinical Practice Guidelines. Rockville: United States Department of Health and Human Services; Public Health Service, 2000.

17. Pipe A, Sorensen M, Reid R. Physician smoking status, attitudes toward smoking, and cessation advice to patients: An international survey. Patient Educ Couns 2009;74:118-23.

18. Papadakis S. Integrating smoking cessation into routine primary care practice: Identifying effective strategies for your practice. smoking cessation rounds. 2007;9:1-6.

19. Britt E, Hudson SM, Blampied NM. Motivational interviewing in health settings: A review. Patient Educ Couns 2004;53:147-55.

20. Herie M, Selby P. Getting beyond, "Now is not a good time to quit smoking." Smoking Cessation Rounds 2007,1:1-6.

21. Silagy C, Lancaster T, Stead L, Mant D, Fowler G. Nicotine replacement therapy for smoking cessation. Cochrane Database Syst Rev 2004:CD000146.

22. Hurt R, Sachs D, Glover E, et al. A comparison of sustained-release bupropion and placebo for smoking cessation. N Engl J Med 1997;337:1195-202.

23. CHAMPIX (varenicline tartrate) - Product Monograph. May 15, 2008.
24. Jorenby DE, Hays JT, Rigotti NA, et al; Varenicline Phase 3 Study Group. Efficacy of varenicline, an alpha4beta2 nicotinic acetylcholine receptor partial agonist, vs placebo or sustainedrelease bupropion for smoking cessation: A randomized controlled trial. JAMA. 2006;296:56-63.

25. Eisenberg MJ, Filion KB, Yavin D, et al. Pharmacotherapies for smoking cessation: A meta-analysis of randomized controlled trials. CMAJ 2008;179:135-44.

26. National Institute for Health and Clinical Excellence. Varenicline for smoking cessation: Final appraisal determination, 2007. $<$ http://guidance.nice.org.uk/page.aspx? $\mathrm{o}=431452>$ (Version current at July 28, 2008).

27. US Food and Drug Administration, Center for Drug Evaluation and Research. Varenicline (marketed as Chantix) information. Washington, DC: United States Department of Health and Human Services, 2008. < http://www.fda.gov/CDER/Drug/infopage/ varenicline/default.htm> (Version current at July 28, 2008).

28. New safety information regarding Champix (varenicline tartrate) for health professionals. <http://www.hc-sc.gc.ca/dhp-mps/alt_ formats/hpfb-dgpsa/pdf/medeff/champix_hpc-cps-eng.pdf> (Version current at August 10, 2008).

29. Rigotti NA, Munafo MR, Stead LF. Interventions for smoking cessation in hospitalised patients. Cochrane Database Syst Rev 2007:CD001837.

30. Molyneux A, Lewis S, Leivers U, et al. Clinical trial comparing nicotine replacement therapy (NRT) plus brief counselling, brief counselling alone, and minimal intervention on smoking cessation in hospital inpatients. Thorax 2003;58:484-8.

31. Simon JA, Carmody TP, Hudes ES, Snyder E, Murray J. Intensive smoking cessation counselling versus minimal counselling among hospitalized smokers treated with transdermal nicotine replacement: A randomized trial. Am J Med 2003;114:555-62.

32. Macleod ZR, Charles MA, Arnaldi VC, Adams IM. Telephone counselling as an adjunct to nicotine patches in smoking cessation: A randomised controlled trial. Med J Aust 2003;179:349-52.

33. Lacasse Y, Lamontagne R, Martin S, Simard S, Arsenault M. Randomized trial of a smoking cessation intervention in hospitalized patients. Nicotine Tob Res 2008;10:1215-21.

34. Reid RD, Pipe AL, Quinlan B. Promoting smoking cessation during hospitalization for coronary artery disease. Can J Cardiol 2006;22:775-80.

35. DE O'Donnell, S Aaron, J Bourbeau, et al. Canadian Thoracic Society recommendations for management of chronic obstructive pulmonary disease - 2007 update. Can Respir J 2007;14(Suppl B):5B-32B.

36. Ontario Lung Association. Proposal for a comprehensive COPD strategy for Ontario. <http://www.on.lung.ca/News-andAnnouncements/COPD-Strategy-Press-Release.pdf $>$ (Version current at July 28, 2008).

37. The Canadian Lung Association. The National Lung Health Framework. <http://www.lung.ca/about-propos/framework-cadre_e. php $>$ (Version current at July 29, 2008).

38. Bonnie RJ, Stratton K, Wallace RB, eds. Ending the tobacco problem: A blueprint for the nation. Washington, DC: The National Academies Press, 2007. <http://www.nap.edu/ catalog/11795.html $>$ (Version current at July 29, 2008).

39. Cunningham JA, Selby PL. Intentions of smokers to use free nicotine replacement therapy. CMAJ 2008;179:145-6.

40. Fiore MC, Jaén CR, Baker TB, et al. Clinical Practice Guideline. Treating Tobacco Use and Dependence: 2008 Update. <http://www. surgeongeneral.gov/tobacco/treating_tobacco_use08.pdf> (Version current at July 29, 2008). 


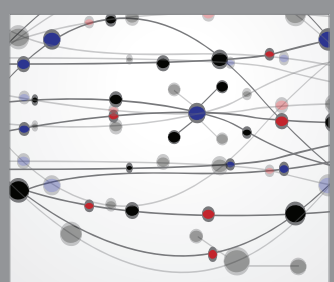

The Scientific World Journal
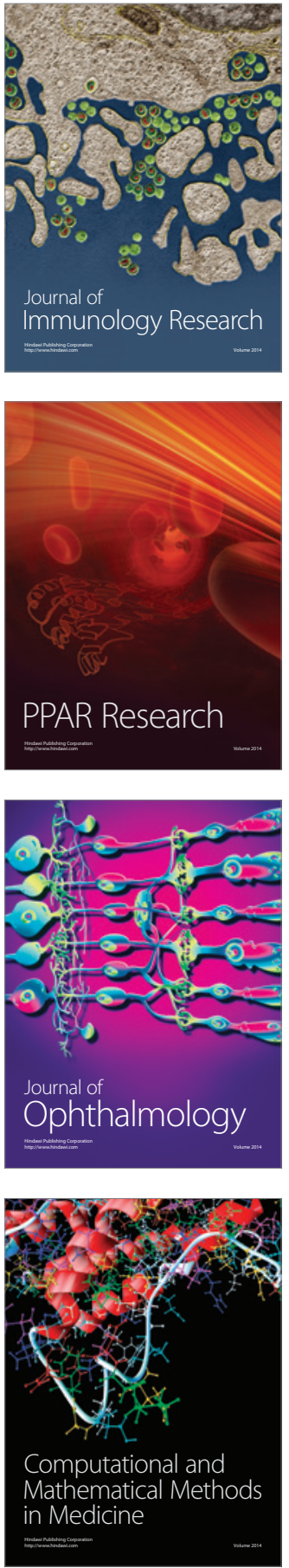

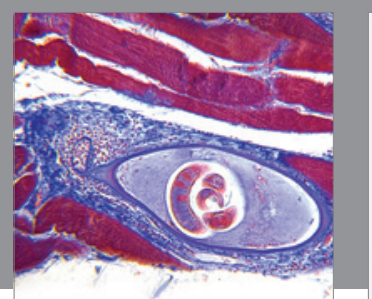

Gastroenterology Research and Practice

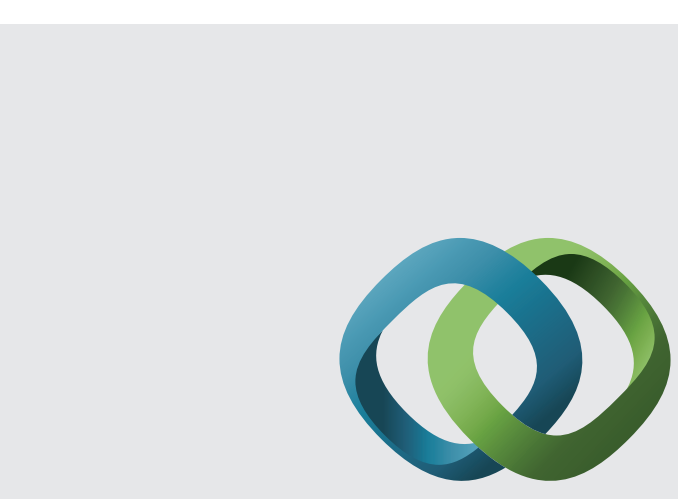

\section{Hindawi}

Submit your manuscripts at

http://www.hindawi.com
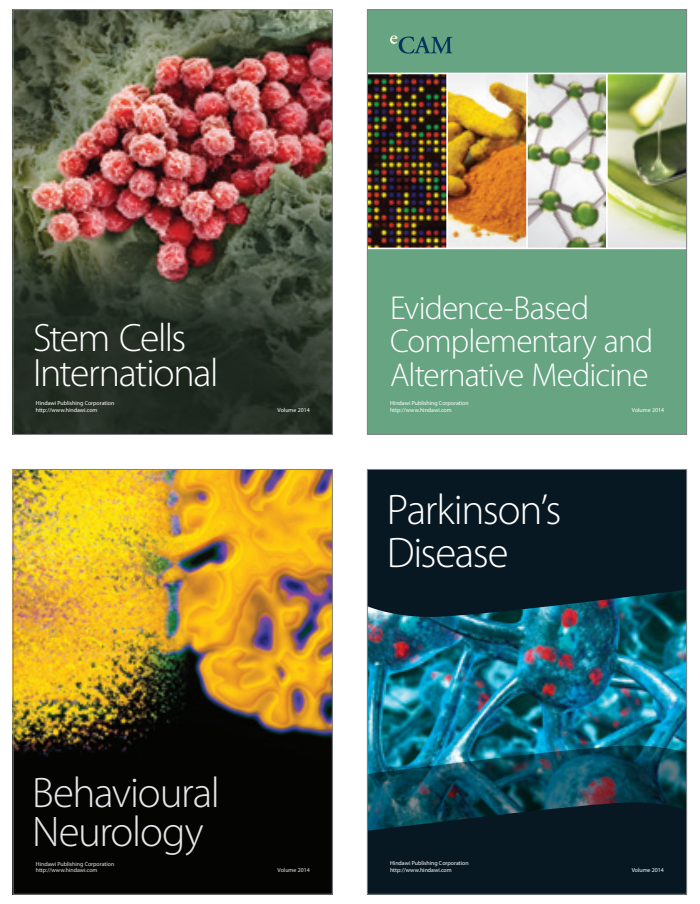
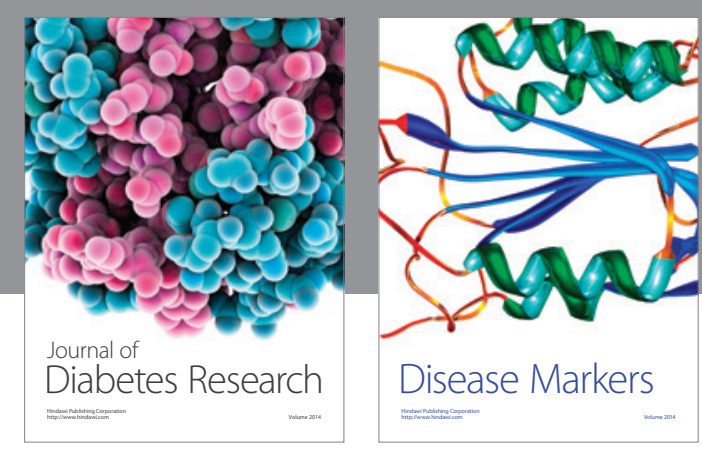

Disease Markers
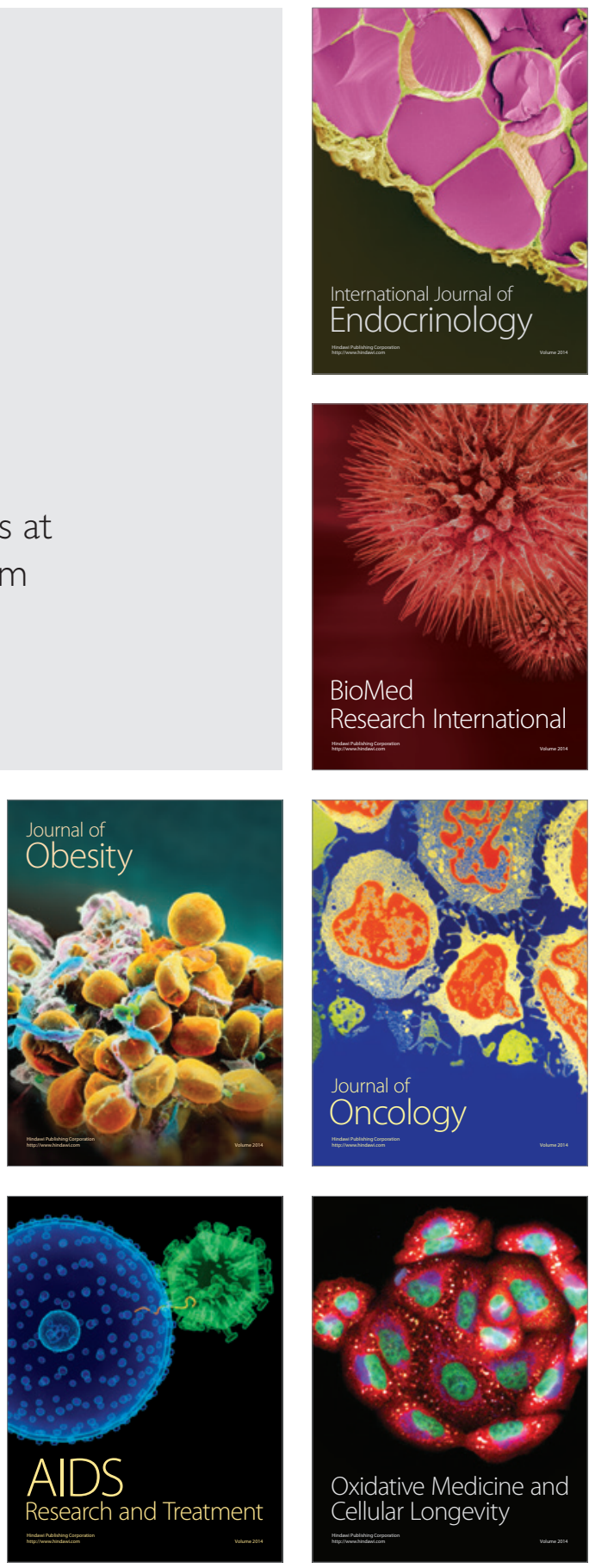